\title{
Evaluating Patient-Centered Mobile Health Technologies: Definitions, Methodologies, and Outcomes
}

Courtenay Bruce ${ }^{1}$, JD, MA; Patricia Harrison ${ }^{1}$, BSN, RN, MBA; Charlie Giammattei ${ }^{2}$, BA; Shetal-Nicholas Desai ${ }^{3,4}$, DPM, MBA; Joshua R Sol ${ }^{3,4}$, BSc; Stephen Jones ${ }^{5,6}$, MD, MSHI; Roberta Schwartz ${ }^{3}$, PhD

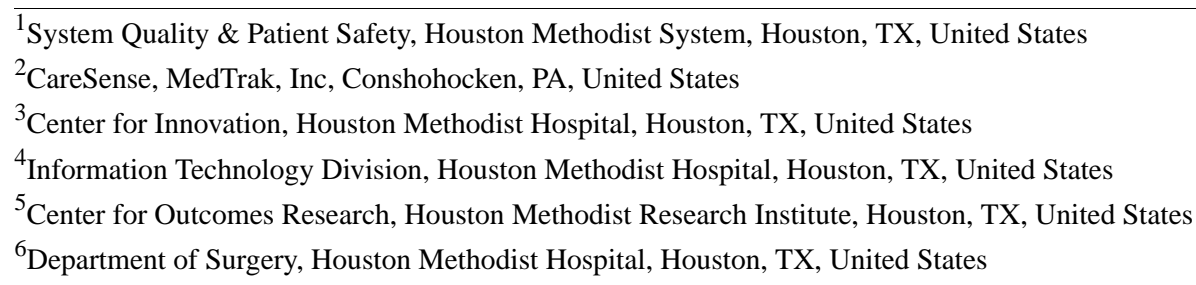

Corresponding Author:

Courtenay Bruce, JD, MA

System Quality \& Patient Safety

Houston Methodist System

6565 Fannin Street

Houston, TX, 77030

United States

Phone: 12816209040

Email: crbruce@ houstonmethodist.org

\section{Abstract}

Several recently published studies and consensus statements have demonstrated that there is only modest (and in many cases, low-quality) evidence that mobile health (mHealth) can improve patient clinical outcomes such as the length of stay or reduction of readmissions. There is also uncertainty as to whether mHealth can improve patient-centered outcomes such as patient engagement or patient satisfaction. One principal challenge behind the "effectiveness" research in this field is a lack of common understanding about what it means to be effective in the digital space (ie, what should constitute a relevant outcome and how best to measure it). In this viewpoint, we call for interdisciplinary, conceptual clarity on the definitions, methodologies, and patient-centered outcomes frequently used in mHealth research. To formulate our recommendations, we used a snowballing approach to identify relevant definitions, outcomes, and methodologies related to mHealth. To begin, we drew heavily upon previously published detailed frameworks that enumerate definitions and measurements of engagement. We built upon these frameworks by extracting other relevant measures of patient-centered care, such as patient satisfaction, patient experience, and patient activation. We describe several definitional inconsistencies for key constructs in the mHealth literature. In an effort to achieve clarity, we tease apart several patient-centered care outcomes, and outline methodologies appropriate to measure each of these patient-care outcomes. By creating a common pathway linking definitions with outcomes and methodologies, we provide a possible interdisciplinary approach to evaluating mHealth technologies. With the broader goal of creating an interdisciplinary approach, we also provide several recommendations that we believe can advance mHealth research and implementation.

(JMIR Mhealth Uhealth 2020;8(11):e17577) doi: $10.2196 / 17577$

\section{KEYWORDS}

innovation; health care; digital technology; digital interventions; patient-facing technologies; patient-centered care; patient centeredness; patient experience; patient engagement; patient activation; quality; effectiveness; quality improvement; information technologies; outcomes; readmissions; length of stay; patient adherence

\section{Background}

Mobile health (mHealth) is defined by the Word Health Organization as "medical and public health practice supported by mobile devices, such as mobile phones, patient monitoring devices, personal digital assistance, and other wireless devices" $[1,2]$. mHealth is considered the future of health care $[3,4]$, and many health care organizations have embraced mHealth as part of their patient-centered initiatives. Specifically, according to a US News \& World report, 18 of the top 20 medical centers 
have adopted and widely celebrated mHealth technologies, at least in a review we conducted of their websites [5]. The National Institutes of Health funding for developing, testing, and implementing mHealth interventions grew from US \$16.8 million in 2014 to US \$39.4 million in 2018 [6].

Despite the growth and hype of mHealth technologies, there is a paucity of effectiveness evidence in the literature to support such widespread implementation [6]. Several recently published studies and consensus statements have demonstrated that there is only modest (and in many cases, low-quality) evidence that mHealth can improve patient clinical outcomes such as lengths of stay or reduction of readmissions [6-9]. There is also uncertainty as to whether mHealth can improve patient-centered outcomes such as patient engagement or patient satisfaction [6-10]. One principal challenge behind the "effectiveness" research is a lack of shared understanding about what it means to be effective in the digital space (ie, what should constitute a relevant outcome and how best to measure it) [2]. This lack of a shared understanding can likely be attributed to the multidisciplinary, multifaceted nature of mHealth, often involving disciplines such as engineering, data science, systems science, human-computer interaction, behavioral sciences, public health, and medicine [10-13]. Each discipline tends to frame its effectiveness research in terms of its own specialized knowledge [13], thereby limiting the generalizability of research results across domains.

In this viewpoint, we call for interdisciplinary, conceptual clarity on the definitions, methodologies, and patient-centered outcomes frequently used in mHealth research. There have been recent, important calls in the literature for conceptual clarity about engagement [6,10-13]; however, as we demonstrate below, engagement is only one facet of patient-centered care [14] and it is not always clear that sustained engagement is required to achieve mHealth outcomes [2]. Stated differently, a shared understanding about engagement is necessary but not sufficient for an interdisciplinary research approach. Conceptual clarity on engagement can only go so far to reduce the current fragmentation of research efforts [12]. Instead, what is needed is consideration beyond one measure of patient-centered care to include several measures of patient-centered care and the methods for evaluating them. By creating a common pathway linking definitions with outcomes and methodologies, we hope to draw a comprehensive (but not necessarily exhaustive) outline of a possible interdisciplinary approach to evaluating mHealth technologies.

To formulate our recommendations, we used a snowballing approach to identify relevant definitions, outcomes, and methodologies related to mHealth. To begin, we drew heavily upon the work of Perski et al [12], Yardley et al [6,13], and Short et al [10], among others [14,15], whose detailed frameworks enumerate the definitions and measurements of engagement [15]. We built upon their frameworks by extracting other relevant measures of patient-centered care, such as patient satisfaction, patient experience, and patient activation, drawing on the quality and patient safety literature-a literature base that has, thus far, to our knowledge, been largely untapped in the mHealth context.
Quality health care refers to care that is safe, effective, patient-centered, timely, efficient, and equitable $[11,16]$. In the mHealth context, most of the work comes from informaticians rather than health care quality practitioners. Theory-based informatics research must be informed by the frontline real-world, hospital environment where health care quality takes place, because patients are different than consumers or research participants [11,17]. Patients experience a constellation of complex, emotionally laden perspectives during their use of mHealth technology that may not be considered when conducting informatics research outside of the hospital setting [18]. The field of health care quality can help advance mHealth research in its evidence-based emphasis on the patient, his or her experiences, and how the continuum of care can influence outcomes that matter to the patient $[19,20]$.

A data extraction table was used to sort, explore, and synthesize existing research (see Multimedia Appendix 1). We filtered and coded our findings based on whether a definition was proposed, whether outcome measures were discussed (and what the outcome measures were), and methodologies used to assess the outcomes. We reran the search queries that were performed in 5 recent, frequently cited systematic reviews [6,12,14,21,22] using the Medline, PsycINFO, PubMed, and Google Scholar databases. Although we did not intend to perform a systematic review for this Viewpoint, we believe that this research approach was comprehensive and could be used to formulate recommendations based on gaps and inconsistencies in the literature.

\section{Defining Patient-Centered mHealth Technologies}

A survey of the literature highlights the myriad terms used in mHealth and the various ways in which they are defined. The terms "mHealth," "telehealth," "eHealth," and "digital technologies" are often treated synonymously [23], although, in reality, they could be different in that eHealth or digital technologies can encompass devices that are not supported by mobile means, such as hospital check-in or registration portals to more advanced technologies designed to enhance patient understanding through education and communication such as Smart Boards and Smart TVs located on hospital units [24].

Digital behavior change interventions (DBCIs) are a subset of eHealth, defined as "a product or service that uses computer technology to promote behavior change," which can be delivered through computer programs, websites, mobile phones as text message, smartphone apps, or wearable devices [6].

Patient-centered care is a health care quality indicator proposed by the Institute of Medicine (IOM) [25]. Patient-centered care has generally been poorly defined, with authors often conflating several distinct concepts such as using the term "patient-centered care" when they are usually referring to a specific outcome measure of patient-centered care [26]. As the IOM explains, patient-centered care is care that is "respectful of and responsive to individual patient preferences, needs, and values, and ensuring that patient values guide all clinical decisions" [25]. Through this lens, patient-centered care can be conceptualized as an 
overarching, broad concept that puts emphasis on respecting patients as a means of honoring their dignity and worth [26,27]. By extension, patient-centered mHealth technologies can be defined as technologies supported by mobile devices designed to promote patient-centered care. There are several outcome measures for patient-centered care.

\section{Patient-Centered Care Outcomes for Patient-Centered mHealth Technologies}

"Patient experience" is likely the strongest, most proximate outcome measure of patient-centered care. Patient experience refers to any process observable by patients, including subjective experiences (eg, pain control) and their objective experiences (eg, wait time) $[28,29]$. A primary feature of patient experience is that it reflects actual health care experiences [30]. Another important feature of patient experience is that it refers to a time sequence. Specifically, patient experience can refer to the first touchpoint within an episode of care (eg, being assessed for a left knee replacement) to the last touchpoint within that episode (eg, last follow-up appointment following surgery for a left knee replacement). Alternatively, patient experience can refer to the whole continuum of care-their first encounter with Hospital A to their last encounter with Hospital A.

"Patient engagement" and "patient activation" are two outcome measures of patient-centered care that are distinct from patient experience. In particular, "patient engagement" has been defined in various ways in the literature [14,30,31]. Recent proposals for integrative definitions of engagement have defined engagement as consisting of objective and subjective components $[6,12,13]$. The objective component is the extent (eg, amount, frequency, duration, and depth) of usage of the mHealth technology [12]. With respect to what constitutes sufficient objective engagement, the literature demonstrates a palpable lack of consensus [15,31]. Some researchers have proposed that a certain empirical threshold of engagement must be met to show sufficient engagement with the intervention to achieve intended outcomes [13], whereas others suggest that one critical point of engagement or fluid, ebbing, and flowing engagement may be sufficient [32,33]. The subjective element of engagement is often characterized by the user's attention, interest, and affect - their overall experience in engaging with the specific mHealth technology $[10,12]$.

"Patient activation" is a patient-centered care outcome measure that refers to patients" "willingness and ability to take independent actions to manage their health," such as avoiding health-damaging behaviors and adopting healthy lifestyle choices, including exercising regularly, eating well, or monitoring their glucose levels [34]. DBCIs usually attempt to evaluate patient activation [34-36], although they may indicate that they are designed to assess adherence or engagement. "Adherence" is often confused with "engagement" and has been defined in at least three separate ways: adherence could refer to whether the intervention is used as intended by the developers [10,32], the usage of mHealth [37] (which is more accurately called engagement), or the patient's willingness and ability to adhere to the recommendations provided by their physician or health care provider (which is likely the most common use of the word "adherence" in medico-legal parlance) [35,38-40].

Taken together, patient engagement typically refers to patients' engagement with an intervention itself, whereas patient activation refers to patients' physical and mental health-related activities based on what they learned from an intervention $[34,41]$. Patients can be engaged by, for example, reading digital messages on the importance of exercising and still not be activated to start exercising [34].

Patient engagement and activation are distinct outcome measures from patient experience in that patient experience refers to patients' perceptions of others' actions, whereas patient engagement and activation refer to patients' actions [27,42]. Patient experience, engagement, and activation are all measures of patient-centered care in that they put emphasis on the patient playing an integral role in their outcomes [43,44], with the ultimate decision-making authority resting with patients. Further, all three concepts can be evaluated empirically.

Finally, "patient satisfaction" is the most attenuated outcome measure of patient-centered care. Patient satisfaction is a term that is often used in health care quality parlance and yet is frequently misunderstood [27] owing to one key feature of satisfaction that is often ignored: satisfaction has little to do with quality [22,27,29]. Patient satisfaction only refers to whether patients' expectations were met $[22,27]$. Patients can be satisfied with care that is low quality and yet be dissatisfied with high-quality care. For this reason, it is incorrect to say that the Hospital Consumer Assessment of Healthcare Provider and Systems survey, the first standardized, publicly reported survey of patient perspectives [45], measures patient satisfaction when, in actuality, the survey uses patient experience as its primary measure for patient-centered care $[27,28,46]$.

As the above discussion illustrates, to date, we have not achieved a shared understanding of important mHealth constructs, or how to conceptualize and operationalize them [10]. Thus, if the mHealth community is to continue to promote the use of patient-centered mHealth technologies (ie, mHealth technologies that are designed with the goal of promoting patient-centered care, as measured by patient experience, patient engagement, patient activation, or patient satisfaction), then we need precision in our terminology to extrapolate generalizable, transferable results $[6,31]$.

\section{Methodologies Used to Empirically Assess Patient-Centered Outcomes}

To validly measure a concept, there must be a tight linkage between the patient-centered care construct (ie, the outcome measure) and items developed for measurement [47]. Below, we describe several methodologies that can assess each patient-centered outcome.

\section{Patient Experience}

There are several qualitative methodologies that are ideal for assessing patient experience. Focus groups, semistructured interviews, observational studies, patient journey mapping, and walk-throughs are all appropriate to assess patient experience 
$[21,29,48,49]$. Semistructured interviews (where the interviewer uses a structured guide to aid conversation) are most helpful to elicit patients' experiences, as well as to elicit particular informational and decisional needs. For example, consider an mHealth technology that provides educational messages (through text and email) to prepare and inform patients about their upcoming surgery. Asking patients to reflect on whether they had gaps in knowledge after completion of the module (eg, gaps in knowledge about surgery lifestyle impacts, surgical risks/benefits, and technical aspects of the surgery, or recovery trajectories and activities) would help elicit patients' informational needs [29].

To assess patient experience, researchers should aim to elicit both definitional components of patient experience: (a) patients' subjective and objective assessments of what occurred, and (b) patients' observations across the full sequence of time [28,45]. Thus, if only one touchpoint of care within an episode is evaluated-such as patient experiences using a digital check-in registration system during a scheduled surgery - then it likely cannot be said that patient experience was fully assessed. A more precise methodology would be one in which teams systematically evaluate patient experiences through all touchpoints using walk-throughs or patient journey mapping, starting from appointment scheduling, to the registration check-in, to the digital navigation system that shows patients how to get to a particular department, to the Smart TVs or Smart Boards within the patients' hospital rooms, and all the way to the patients' beside tablet-based and electronic health record solutions [50-52]. The goal of walk-throughs and journey mapping is to ask patients what they are feeling, seeing, and experiencing as they move from, say, the registration portal to a patient room [50].

\section{Patient Engagement}

Short and colleagues [10] describe several methodologies that are appropriate to evaluate patient engagement. To assess patient engagement, researchers should aim to elicit both definitional components of patient engagement: the objective component, as the extent (eg, amount, frequency, duration, and depth) of usage of the mHealth technology, as well users' subjective assessment in using the mHealth technology [13]. The objective component is likely best evaluated using quantitative measures such as the number of login attempts, the time spent on a technology, the time spent reading a particular message or conducting an e-module, or the amount of bidirectional communication between a patient and provider using an mHealth technology [11,13,53-58]. The subjective component of engagement can likely best be evaluated using qualitative methodologies such as semistructured interviews and focus groups, which tend to be most appropriate for teasing out themes, as well as users' beliefs, narratives, and perceptions [23].

\section{Patient Activation}

There is a heavy behavioral dimension to patient activation - what the patient does in response to the intervention in terms of his or her health-related activities - which can be assessed quantitatively [58,59]. Several studies that claim to measure patient engagement are arguably instead measuring patient activation [60-62]. Whether a patient had higher medication adherence [63,64], higher levels of physical exercise $[9,65,66]$, or improved diabetes management as a result of the mHealth intervention $[67,68]$ can be considered patient activation if the patient took healthy actions based on what he/she learned through the mHealth technology. These medical, clinically based health outcomes can be empirically derived using electronic medical records. There are also validated, reliable quantitative measures available to evaluate patient activation $[58,59]$.

\section{Patient Satisfaction}

Patient satisfaction is generally considered to be the most attenuated outcome measure for patient-centered mHealth technologies and thus can likely be assessed from a purely descriptive [69] quantitative point of view, devoid of any thematic nuancing that qualitative measures can afford. There are numerous quantitative measures available to evaluate patient satisfaction, although the validity and reliability of the instruments have been a point of debate [69-80].

Table 1 outlines a common pathway linking definitions with outcomes and methodologies. The table is not intended to be exhaustive but is instead designed to provide a robust set of patient-centered constructs, outcome measures, and methodologies. In this summary, we refrained from including strictly objective, physiological measures because the patient-centered constructs depend heavily on the subjective experience of patients, which physiological measures often cannot elicit. 
Table 1. Patient-centered mobile health (mHealth) technologies: outcome measures, methodologies, and definitions.

\begin{tabular}{|c|c|c|c|c|}
\hline \multirow[t]{2}{*}{$\begin{array}{l}\text { Outcome mea- } \\
\text { sures }\end{array}$} & \multirow[t]{2}{*}{ Definitions } & \multicolumn{2}{|l|}{ Methodologies } & \multirow[t]{2}{*}{$\begin{array}{l}\text { Example mHealth Technolo- } \\
\text { gies }\end{array}$} \\
\hline & & Qualitative & Quantitative & \\
\hline \multirow[t]{4}{*}{$\begin{array}{l}\text { Patient experi- } \\
\text { ence }\end{array}$} & \multirow{4}{*}{$\begin{array}{l}\text { Any process observable by pa- } \\
\text { tients, including subjective expe- } \\
\text { riences (eg, pain control) and } \\
\text { their objective experiences (eg, } \\
\text { wait time). Must refer to the en- } \\
\text { tire sequence in the care episode } \\
\text { or full continuum of care-from }\end{array}$} & Semistructured interviews & $\begin{array}{l}\text { Walk-throughs (eg, the Walk Through } \\
\text { Tool [48]) }\end{array}$ & $\begin{array}{l}\text { Touchscreen kiosks for reg- } \\
\text { istration or check-in }\end{array}$ \\
\hline & & & Patient Journey Mapping Tool $[49,50]$ & Digital navigation systems \\
\hline & & & $\begin{array}{l}\text { Impact of Assistive Devices Scale } \\
\text { (PIADS) [51] }\end{array}$ & $\begin{array}{l}\text { to help patients navigate the } \\
\text { hospital }\end{array}$ \\
\hline & & & & Smart TVs in hospital rooms \\
\hline
\end{tabular}

Patient engage- The extent (eg, amount, frequenment cy, duration, and depth) of usage of the mHealth technology, coupled with the user's subjective assessment in using the mHealth technology.

Patient activation

Patient satisfaction
Willingness and ability to take independent actions to manage their health

Whether a patient's expectations were met.
Semistructured interviews Think aloud exercises Focus groups
Self-report questionnaires (eg, the eHealth Engagement Scale and the Digital Behavior Change Intervention Engagement Scale [52])

Usability and acceptability scales (eg, The mHealth App Usability Questionnaire [MAUQ] [53])

Social Networking Time Use Scale (SONTUS) [54]

Facebook Intensity Scale (FBI Scale) [55]

Media and Technology Usage and Attitudes Scale (MTUAS) [56]

Chinese Internet Gaming Disorder Scale [57]

Number of logins; time spent on mHealth; time spent reading a message; number of monitoring questions for which there was a response

Focus groups, semistructured interviews

Patient Activation Measure (PAM) [58,59]

Short Assessment of Patient Satisfaction (SAPS) [60]

Risser Patient Satisfaction Scale [61]

Patient Satisfaction Questionnaire (PSQ) (multiple iterations) [62]

Quebec User Evaluation of Satisfaction with Assistive Technology (QUEST) [63]
Two-way bidirectional communication on a communication or education mobile platform

Secure SMS text message/email/push notifications, self-scheduling, medical record access, patientprovider messaging, and bill pay
Digital behavior change interventions

Patient biosensor monitoring devices (eg, glucose monitoring kits)

Patient-reported outcomes collection via mHealth

\section{Recommendations}

Above, we have described several definitional inconsistencies for key constructs in the mHealth literature. In an effort to achieve clarity, we teased apart several patient-centered care outcomes, and we outline methodologies appropriate to measure each of the patient-care outcomes (Table 1). In what follows, we provide recommendations for evaluating mHealth patient-centered technologies. Our recommendations relate to the patient-centered constructs in that we advocate for patients taking center stage in mHealth research and collaboration efforts to enhance patient experience, patient engagement, patient activation, and patient satisfaction.

\section{Recommendation 1: Use Patients When Assessing Patient-Centered Care mHealth Technologies}

Patient participation is a central tenet of ethically driven research and product development [81-83]. Unfortunately, much of mHealth research only engages patients in the beginning phases during agenda-setting and protocol development [83]. Systematic reviews have found that little research involves patients throughout the development, implementation, and modification phases of mHealth patient-centered technologies $[83,84]$. Reviews have also found that patient participation is often treated as a tokenistic measure, one in which patients' feedback is used primarily as a means of "rubberstamping" to secure funding or to approve a previously chosen decision made 
by the research or design team, rather than using patients as principal drivers of decision-making [83,84].

The main reason that patient participation is integral to conducting ethically driven mHealth research and product development is because patients are unique $[42,85]$; they should not be viewed as the same type of customers found in other sectors [6]. For instance, customers of any other good or service have luxuries that patients may not have. Patients become consumers, arguably not by choice but rather by need. Patients' preferences are largely unknown when the good or service is used, and they have limited channels of communication and limited control [42]. Patients likely experience physical or emotional impairments such as fears, grief, and anxiety while using the service [86]. All of these factors likely suggest that a particular patient's informational and decision-making needs are different from those that they would have outside of a health care context [86-89]. Patient participation and active engagement are the classic tenets of task, user, representation, and functional analysis used to inform system designers and leadership that are contemplating implementing solutions to patient-centered problems [87-89].

\section{Recommendation 2: Create an International Collaboration to Enhance the Quality and Effectiveness of mHealth Technologies}

mHealth technologies are the future for patient-centered care $[3,74]$. However, the extent to which mHealth technologies influence or impact patient-centered care is unclear [6], which is likely owing to the imprecision in definitions, methodological approaches, and disjointed interests of multiple stakeholders within health care organizations and industry [2].

We contend that some form of self-regulation or an internationally used assessment framework is needed to ensure that quality standards are met before wide-scale dissemination of any patient-centered mHealth technology [2]. The US Food and Drug Administration has taken a passive approach, explicitly applying its regulatory oversight to only those software functions that are medical devices and whose functionality could pose a risk to a patient safety if the device were to not function as intended [90]. The European Commission mHealth Green Paper does not give any recommendations [91]. The Health Technology Assessment Agency and its collaborative networks have discussed the importance of a collaborative approach, but, at the time of this writing, have failed to provide some form of a comprehensive evaluative framework [92,93].

When patient decision aids were being developed and implemented at a rapid pace without high-quality evidence, an international collaboration among researchers, practitioners, and stakeholders was instituted to enhance the quality and effectiveness of patient decision aids, called the International Patient Decision Aids (IPDAS) Collaboration [94]. The group established (and routinely revises) an evidence-informed framework, which outlines actions that patient decision-aid developers should take in terms of content-writing, development, implementation, and evaluation. The IPDAS Collaboration "grades" decision aids based on whether and to what degree the aids meet parameters, and the score can be used in marketing and evaluating the patient decision aid [94].

An international collaboration similar to that used for patient decision aids is, we believe, appropriate for the regulation and systematic evaluation of patient-centered mHealth technologies. Similar to patient decision aids, the successful implementation of patient-centered mHealth requires multidisciplinary teams from academia, industry, and health care management sectors, along with patients and consumers working collaboratively to maintain the requisite medical, statistical, information technology, patient-centered, and research expertise necessary to implement and evaluate mHealth technologies [95], which an international collaboration would afford. There are several actions a large collaboration could take to encourage high-quality development and dissemination of digital technologies.

First, because of its large scale, an international collaboration would be well-positioned to help address barriers to electronic interoperability issues that stem from disparate proprietary digital health record systems by, for example, creating digital health data exchange platforms to standardize data [95]. Second, a collaboration could disseminate practical advice on how organizations can use their foundational digital systems to leverage existing capabilities for achieving coordination through bolt-on, incremental development of digital technologies. Third, an international collaboration could build upon our work to develop exhaustive criteria and methodology standards for how to design, produce, implement, and evaluate digital technologies.

\section{Conclusion}

In this Viewpoint, we called for interdisciplinary, conceptual clarity on the definitions, methodologies, and patient-centered outcomes frequently used in mHealth research. In doing so, we advocate for consideration of several measures of patient-centered care, and we outline various methods for evaluating them. By creating a common pathway linking definitions with outcomes and methodologies, we provide a possible interdisciplinary approach to evaluating mHealth technologies.

To that end of creating an interdisciplinary approach, we also provide several recommendations that we believe can advance mHealth research and implementation. For instance, if an international collaboration were created to develop evaluative criteria, using the guidance provided here to ground criteria development, then low-quality digital technologies would likely be excluded. Transparency and precision would be promoted, large-scale published evidence would be encouraged [3], and mHealth technologies could finally flourish within a high-quality, patient-centered landscape.

\section{Conflicts of Interest}

None declared. 


\section{Multimedia Appendix 1}

Data Abstraction Table.

[XLSX File (Microsoft Excel File), 37 KB-Multimedia Appendix 1]

\section{References}

1. Frequently asked questions on Global Task Force on digital health for TB and its work. World Health Organization. URL: http://www.who.int/tb/areas-of-work/digital-health/faq/en/ [accessed 2020-11-03]

2. Bradway M, Carrion C, Vallespin B, Saadatfard O, Puigdomènech E, Espallargues M, et al. mHealth Assessment: Conceptualization of a Global Framework. JMIR Mhealth Uhealth 2017 May 02;5(5):e60 [FREE Full text] [doi: 10.2196/mhealth.7291] [Medline: 28465282]

3. Smith B, Sverdlov A. Digital Technology: The Future Is Bright. Clin Pharmacol Ther 2018 Jul;104(1):9-11. [doi: 10.1002/cpt.1092] [Medline: 29890004]

4. Alami H, Gagnon M, Fortin J. Digital health and the challenge of health systems transformation. Mhealth 2017;3:31. [doi: 10.21037/mhealth.2017.07.02] [Medline: 28894741]

5. Health News Articles. US News \& World Report Health. URL: https://health.usnews.com/ [accessed 2020-11-03]

6. Michie S, Yardley L, West R, Patrick K, Greaves F. Developing and Evaluating Digital Interventions to Promote Behavior Change in Health and Health Care: Recommendations Resulting From an International Workshop. J Med Internet Res 2017 Jun 29;19(6):e232 [FREE Full text] [doi: 10.2196/jmir.7126] [Medline: 28663162]

7. Donevant SB, Estrada RD, Culley JM, Habing B, Adams SA. Exploring app features with outcomes in mHealth studies involving chronic respiratory diseases, diabetes, and hypertension: a targeted exploration of the literature. J Am Med Inform Assoc 2018 Oct 01;25(10):1407-1418 [ [FREE Full text] [doi: 10.1093/jamia/ocy104] [Medline: $\underline{\text { 30137383] }}$

8. Aitken M, Lyle J. Patient Adoption of mHealth: Use, Evidence and Remaining Barriers to Mainstream Acceptance. Parsippany, NJ: IMS Institute for Healthcare Informatics; 2015.

9. Patnode CD, Evans CV, Senger CA, Redmond N, Lin JS. Behavioral Counseling to Promote a Healthful Diet and Physical Activity for Cardiovascular Disease Prevention in Adults Without Known Cardiovascular Disease Risk Factors: Updated Evidence Report and Systematic Review for the US Preventive Services Task Force. JAMA 2017 Jul 11;318(2):175-193. [doi: 10.1001/jama.2017.3303] [Medline: 28697259]

10. Short CE, DeSmet A, Woods C, Williams SL, Maher C, Middelweerd A, et al. Measuring Engagement in eHealth and mHealth Behavior Change Interventions: Viewpoint of Methodologies. J Med Internet Res 2018 Nov 16;20(11):e292 [FREE Full text] [doi: 10.2196/jmir.9397] [Medline: 30446482]

11. Shekelle PG, Pronovost PJ, Wachter RM, Taylor SL, Dy SM, Foy R, et al. Advancing the science of patient safety. Ann Intern Med 2011 May 17;154(10):693-696. [doi: 10.7326/0003-4819-154-10-201105170-00011] [Medline: 21576538]

12. Perski O, Blandford A, West R, Michie S. Conceptualising engagement with digital behaviour change interventions: a systematic review using principles from critical interpretive synthesis. Transl Behav Med 2017 Jun;7(2):254-267 [FREE Full text] [doi: 10.1007/s13142-016-0453-1] [Medline: 27966189]

13. Yardley L, Spring BJ, Riper H, Morrison LG, Crane DH, Curtis K, et al. Understanding and Promoting Effective Engagement With Digital Behavior Change Interventions. Am J Prev Med 2016 Nov;51(5):833-842. [doi: 10.1016/j.amepre.2016.06.015] [Medline: 27745683]

14. Sawesi S, Rashrash M, Phalakornkule K, Carpenter JS, Jones JF. The Impact of Information Technology on Patient Engagement and Health Behavior Change: A Systematic Review of the Literature. JMIR Med Inform 2016 Jan 21;4(1):e1 [FREE Full text] [doi: 10.2196/medinform.4514] [Medline: 26795082]

15. Carman KL, Dardess P, Maurer M, Sofaer S, Adams K, Bechtel C, et al. Patient and family engagement: a framework for understanding the elements and developing interventions and policies. Health Aff (Millwood) 2013 Feb;32(2):223-231. [doi: 10.1377/hlthaff.2012.1133] [Medline: 23381514]

16. About health care quality. US Department of Health and Human Services Office of Disease Prevention and Health Promotion. URL: https://health.gov/our-work/health-care-quality/about-health-care-quality [accessed 2020-11-03]

17. Davidoff F, Dixon-Woods M, Leviton L, Michie S. Demystifying theory and its use in improvement. BMJ Qual Saf 2015 Mar;24(3):228-238 [FREE Full text] [doi: 10.1136/bmjqs-2014-003627] [Medline: 25616279]

18. Batalden M, Batalden P, Margolis P, Seid M, Armstrong G, Opipari-Arrigan L, et al. Coproduction of healthcare service. BMJ Qual Saf 2016 Jul;25(7):509-517 [FREE Full text] [doi: 10.1136/bmjqs-2015-004315] [Medline: 26376674]

19. Berwick DM, Nolan TW, Whittington J. The triple aim: care, health, and cost. Health Aff (Millwood) 2008;27(3):759-769. [doi: 10.1377/hlthaff.27.3.759] [Medline: 18474969 ]

20. Bodenheimer T, Sinsky C. From triple to quadruple aim: care of the patient requires care of the provider. Ann Fam Med 2014;12(6):573-576 [FREE Full text] [doi: 10.1370/afm.1713] [Medline: 25384822]

21. Newell S, Jordan Z. The patient experience of patient-centered communication with nurses in the hospital setting: a qualitative systematic review protocol. JBI Database System Rev Implement Rep 2015 Jan;13(1):76-87. [doi: 10.11124/jbisrir-2015-1072] [Medline: 26447009] 
22. Batbaatar E, Dorjdagva J, Luvsannyam A, Savino MM, Amenta P. Determinants of patient satisfaction: a systematic review. Perspect Public Health 2017 Mar;137(2):89-101. [doi: 10.1177/1757913916634136] [Medline: 27004489]

23. Njoroge M, Zurovac D, Ogara EAA, Chuma J, Kirigia D. Assessing the feasibility of eHealth and mHealth: a systematic review and analysis of initiatives implemented in Kenya. BMC Res Notes 2017 Feb 10;10(1):90 [FREE Full text] [doi: 10.1186/s13104-017-2416-0] [Medline: 28183341]

24. Lee S, Cho Y, Kim S. Mapping mHealth (mobile health) and mobile penetrations in sub-Saharan Africa for strategic regional collaboration in mHealth scale-up: an application of exploratory spatial data analysis. Global Health 2017 Aug 22;13(1):63 [FREE Full text] [doi: 10.1186/s12992-017-0286-9] [Medline: 28830540]

25. Institute of Medicine (US) Committee on Quality of Health Care in America. Crossing the Quality Chasm: A New Health System for the 21st Century. Washington DC: National Academies Press; 2001.

26. Tzelepis F, Sanson-Fisher RW, Zucca AC, Fradgley EA. Measuring the quality of patient-centered care: why patient-reported measures are critical to reliable assessment. Patient Prefer Adherence 2015;9:831-835. [doi: 10.2147/PPA.S81975] [Medline: 26150703]

27. Cleary PD. Evolving Concepts of Patient-Centered Care and the Assessment of Patient Care Experiences: Optimism and Opposition. J Health Polit Policy Law 2016 Aug;41(4):675-696. [doi: 10.1215/03616878-3620881] [Medline: 27127265]

28. Browne K, Roseman D, Shaller D, Edgman-Levitan S. Health Aff (Millwood) 2010 May;29(5):921-925. [doi: 10.1377/hlthaff.2010.0238] [Medline: 20439881]

29. Anhang Price R, Elliott MN, Zaslavsky AM, Hays RD, Lehrman WG, Rybowski L, et al. Examining the role of patient experience surveys in measuring health care quality. Med Care Res Rev 2014 Oct;71(5):522-554 [FREE Full text] [doi: 10.1177/1077558714541480] [Medline: 25027409]

30. Evans D, Hopewell-Kelly N, Kok M, White J. Synthesising conceptual frameworks for patient and public involvement in research - a critical appraisal of a meta-narrative review. BMC Med Res Methodol 2018 Oct 25;18(1):116 [FREE Full text] [doi: 10.1186/s12874-018-0572-0] [Medline: $\underline{\text { 30359226] }}$

31. O'Brien HL, Toms EG. What is user engagement? A conceptual framework for defining user engagement with technology. J Am Soc Inf Sci 2008 Apr;59(6):938-955. [doi: 10.1002/asi.20801]

32. Oliver S, Clarke-Jones L, Rees R, Milne R, Buchanan P, Gabbay J, et al. Involving consumers in research and development agenda setting for the NHS: developing an evidence-based approach. Health Technol Assess 2004 Apr;8(15):1-148, III [FREE Full text] [doi: 10.3310/hta8150] [Medline: 15080866]

33. Murray E, Hekler EB, Andersson G, Collins LM, Doherty A, Hollis C, et al. Evaluating Digital Health Interventions: Key Questions and Approaches. Am J Prev Med 2016 Nov;51(5):843-851 [FREE Full text] [doi: 10.1016/j.amepre.2016.06.008] [Medline: 27745684]

34. Greene J, Hibbard JH. Why does patient activation matter? An examination of the relationships between patient activation and health-related outcomes. J Gen Intern Med 2012 May;27(5):520-526 [FREE Full text] [doi: 10.1007/s11606-011-1931-2] [Medline: 22127797]

35. Kelders SM, Van Gemert-Pijnen JEWC, Werkman A, Nijland N, Seydel ER. Effectiveness of a Web-based intervention aimed at healthy dietary and physical activity behavior: a randomized controlled trial about users and usage. J Med Internet Res 2011 Apr 14;13(2):e32 [FREE Full text] [doi: 10.2196/jmir.1624] [Medline: 21493191]

36. Shippee ND, Domecq Garces JP, Prutsky Lopez GJ, Wang Z, Elraiyah TA, Nabhan M, et al. Patient and service user engagement in research: a systematic review and synthesized framework. Health Expect 2015 Oct;18(5):1151-1166 [FREE Full text] [doi: 10.1111/hex.12090] [Medline: 23731468]

37. Sieverink F, Kelders SM, van Gemert-Pijnen JE. Clarifying the Concept of Adherence to eHealth Technology: Systematic Review on When Usage Becomes Adherence. J Med Internet Res 2017 Dec 06;19(12):e402 [FREE Full text] [doi: 10.2196/jmir.8578] [Medline: 29212630]

38. Haywood C, Lanzkron S, Bediako S, Strouse JJ, Haythornthwaite J, Carroll CP, IMPORT Investigators. Perceived discrimination, patient trust, and adherence to medical recommendations among persons with sickle cell disease. J Gen Intern Med 2014 Dec;29(12):1657-1662 [FREE Full text] [doi: 10.1007/s11606-014-2986-7] [Medline: 25205621]

39. Martin LR, Williams SL, Haskard KB, Dimatteo MR. The challenge of patient adherence. Ther Clin Risk Manag 2005 Sep;1(3):189-199 [FREE Full text] [Medline: 18360559]

40. Tilson HH. Adherence or Compliance? Changes in Terminology. Ann Pharmacother 2004 Jan;38(1):161-162. [doi: 10.1345/aph.1d207]

41. Hibbard JH, Greene J. What the evidence shows about patient activation: better health outcomes and care experiences; fewer data on costs. Health Aff (Millwood) 2013 Feb;32(2):207-214. [doi: 10.1377/hlthaff.2012.1061] [Medline: 23381511]

42. Boissy A. Better communication makes better physicians. NEJM Catalyst. URL: https://catalyst.nejm.org/doi/full/10.1056/ CAT.17.0377 [accessed 2020-11-03]

43. Dykes PC, Rozenblum R, Dalal A, Massaro A, Chang F, Clements M, et al. Prospective Evaluation of a Multifaceted Intervention to Improve Outcomes in Intensive Care: The Promoting Respect and Ongoing Safety Through Patient Engagement Communication and Technology Study. Crit Care Med 2017 Aug;45(8):e806-e813. [doi: 10.1097/CCM.0000000000002449] [Medline: 28471886] 
44. Black N, Varaganum M, Hutchings A. Relationship between patient reported experience (PREMs) and patient reported outcomes (PROMs) in elective surgery. BMJ Qual Saf 2014 Jul;23(7):534-542. [doi: 10.1136/bmjqs-2013-002707] [Medline: 24508681]

45. HCAHPS: Patients' Perspectives of Care Survey. Centers for Medicare \& Medicaid Services. 2017 Dec 21. URL: https:/ /www.cms.gov/Medicare/Quality-Initiatives-Patient-Assessment-Instruments/HospitalQualityInits/HospitalHCAHPS.html [accessed 2020-11-03]

46. Doyle C, Lennox L, Bell D. A systematic review of evidence on the links between patient experience and clinical safety and effectiveness. BMJ Open 2013 Jan 03;3(1):e001570 [FREE Full text] [doi: 10.1136/bmjopen-2012-001570] [Medline: 23293244]

47. Hamric AB. Empirical research on moral distress: issues, challenges, and opportunities. HEC Forum 2012 Mar 4;24(1):39-49. [doi: 10.1007/s10730-012-9177-x] [Medline: 22476738]

48. Gustafson D. Walk-through Tool. Institute for Healthcare Improvement. URL: http://www.ihi.org/resources/Pages/Tools/ Walkthrough.aspx [accessed 2020-11-03]

49. Trebble TM, Hansi N, Hydes T, Smith MA, Baker M. Process mapping the patient journey: an introduction. BMJ 2010 Aug 13;341:c4078. [doi: 10.1136/bmj.c4078] [Medline: 20709715]

50. Antonacci G, Reed JE, Lennox L, Barlow J. The use of process mapping in healthcare quality improvement projects. Health Serv Manage Res 2018 May;31(2):74-84. [doi: 10.1177/0951484818770411] [Medline: 29707978]

51. Jutai J, Day H. Psychosocial Impact of Assistive Devices Scale (PIADS). Technol Disab 2002 Sep 29;14(3):107-111. [doi: 10.3233/tad-2002-14305]

52. Perski O, Lumsden J, Garnett C, Blandford A, West R, Michie S. Assessing the Psychometric Properties of the Digital Behavior Change Intervention Engagement Scale in Users of an App for Reducing Alcohol Consumption: Evaluation Study. J Med Internet Res 2019 Nov 20;21(11):e16197 [FREE Full text] [doi: 10.2196/16197] [Medline: 31746771$]$

53. Zhou L, Bao J, Setiawan IMA, Saptono A, Parmanto B. The mHealth App Usability Questionnaire (MAUQ): Development and Validation Study. JMIR Mhealth Uhealth 2019 Apr 11;7(4):e11500 [FREE Full text] [doi: 10.2196/11500] [Medline: 30973342]

54. Olufadi Y. Social networking time use scale (SONTUS): A new instrument for measuring the time spent on the social networking sites. Telemat Inform 2016 May;33(2):452-471. [doi: 10.1016/j.tele.2015.11.002]

55. Ellison NB, Steinfield C, Lampe C. The benefits of Facebook "friends:" Social capital and college students' use of online social network sites. J Comput Mediat Commun 2007;12(1):1143-1168. [doi: 10.1111/j.1083-6101.2007.00367.x]

56. Rosen L, Whaling K, Carrier L, Cheever N, Rokkum J. The Media and Technology Usage and Attitudes Scale: An empirical investigation. Comput Human Behav 2013 Nov 01;29(6):2501-2511 [FREE Full text] [doi: 10.1016/j.chb.2013.06.006] [Medline: 25722534]

57. Sigerson L, Li AY, Cheung MW, Luk JW, Cheng C. Psychometric properties of the Chinese Internet Gaming Disorder Scale. Addict Behav 2017 Nov;74:20-26 [FREE Full text] [doi: 10.1016/j.addbeh.2017.05.031] [Medline: 28558336]

58. Hibbard JH, Stockard J, Mahoney ER, Tusler M. Development of the Patient Activation Measure (PAM): conceptualizing and measuring activation in patients and consumers. Health Serv Res 2004 Aug;39(4 Pt 1):1005-1026 [FREE Full text] [doi: 10.1111/j.1475-6773.2004.00269.x] [Medline: 15230939]

59. Maindal HT, Sokolowski I, Vedsted P. Translation, adaptation and validation of the American short form Patient Activation Measure (PAM13) in a Danish version. BMC Public Health 2009 Jun 29;9:209 [FREE Full text] [doi: 10.1186/1471-2458-9-209] [Medline: 19563630 ]

60. Payne HE, Lister C, West JH, Bernhardt JM. Behavioral functionality of mobile apps in health interventions: a systematic review of the literature. JMIR Mhealth Uhealth 2015 Feb 26;3(1):e20 [FREE Full text] [doi: 10.2196/mhealth.3335] [Medline: 25803705]

61. Barello S, Triberti S, Graffigna G, Libreri C, Serino S, Hibbard J, et al. eHealth for Patient Engagement: A Systematic Review. Front Psychol 2015 Jan 08;6:2013. [doi: 10.3389/fpsyg.2015.02013] [Medline: 26779108]

62. DiFilippo KN, Huang W, Andrade JE, Chapman-Novakofski KM. The use of mobile apps to improve nutrition outcomes: A systematic literature review. J Telemed Telecare 2015 Jul;21(5):243-253. [doi: 10.1177/1357633X15572203] [Medline: 25680388]

63. Gandapur Y, Kianoush S, Kelli HM, Misra S, Urrea B, Blaha MJ, et al. The role of mHealth for improving medication adherence in patients with cardiovascular disease: a systematic review. Eur Heart J Qual Care Clin Outcomes 2016 Oct 01;2(4):237-244 [FREE Full text] [doi: 10.1093/ehjqcco/qcw018] [Medline: 29474713]

64. Xiong S, Berkhouse H, Schooler M, Pu W, Sun A, Gong E, et al. Effectiveness of mHealth Interventions in Improving Medication Adherence Among People with Hypertension: a Systematic Review. Curr Hypertens Rep 2018 Aug 07;20(10):86. [doi: 10.1007/s11906-018-0886-7] [Medline: 30088110]

65. Stephens J, Allen J. Mobile phone interventions to increase physical activity and reduce weight: a systematic review. J Cardiovasc Nurs 2013;28(4):320-329 [FREE Full text] [doi: 10.1097/JCN.0b013e318250a3e7] [Medline: 22635061]

66. van den Berg MH, Schoones JW, Vliet Vlieland TPM. Internet-based physical activity interventions: a systematic review of the literature. J Med Internet Res 2007 Sep 30;9(3):e26 [FREE Full text] [doi: 10.2196/jmir.9.3.e26] [Medline: 17942388] 
67. Wu C, Wu Z, Yang L, Zhu W, Zhang M, Zhu Q, et al. Evaluation of the clinical outcomes of telehealth for managing diabetes: A PRISMA-compliant meta-analysis. Medicine (Baltimore) 2018 Oct;97(43):e12962. [doi: 10.1097/MD.0000000000012962] [Medline: 30412116]

68. Greenwood DA, Blozis SA, Young HM, Nesbitt TS, Quinn CC. Overcoming Clinical Inertia: A Randomized Clinical Trial of a Telehealth Remote Monitoring Intervention Using Paired Glucose Testing in Adults With Type 2 Diabetes. J Med Internet Res 2015 Jul 21;17(7):e178-e482 [FREE Full text] [doi: 10.2196/jmir.4112] [Medline: 26199142]

69. Gilling S, Mortz CG, Vestergaard T. Patient Satisfaction and Expectations Regarding Mobile Teledermoscopy in General Practice for Diagnosis of Non-melanoma Skin Cancer and Malignant Melanoma. Acta Derm Venereol 2020 Apr 21;100(8):adv00117 [FREE Full text] [doi: 10.2340/00015555-3459] [Medline: $\underline{\text { 32179927] }}$

70. Hawthorne G, Sansoni J, Hayes L, Marosszeky N, Sansoni E. Measuring patient satisfaction with health care treatment using the Short Assessment of Patient Satisfaction measure delivered superior and robust satisfaction estimates. J Clin Epidemiol 2014 May;67(5):527-537. [doi: 10.1016/j.jclinepi.2013.12.010] [Medline: 24698296]

71. Risser NL. Development of an instrument to measure patient satisfaction with nurses and nursing care in primary care settings. Nurs Res 1975;24(1):45-52. [Medline: 1038021]

72. Marshall G, Hays R. The Patient Satisfaction Questionnaire Short Form (PSQ-18). Santa Monica, CA: RAND Corporation; 1994.

73. Demers L, Weiss-Lambrou R, Ska B. Development of the Quebec User Evaluation of Satisfaction with assistive Technology (QUEST). Assist Technol 1996 Jun 30;8(1):3-13. [doi: 10.1080/10400435.1996.10132268] [Medline: 10159726]

74. mHealth Economics 2017 - Current Status and Future Trends in Mobile Health. research2guidance. 2017. URL: https:/ /research2guidance.com/product/mhealth-economics-2017-current-status-and-future-trends-in-mobile-health/ [accessed 2020-11-03]

75. Nurmi J, Knittle K, Ginchev T, Khattak F, Helf C, Zwickl P, et al. Engaging Users in the Behavior Change Process With Digitalized Motivational Interviewing and Gamification: Development and Feasibility Testing of the Precious App. JMIR Mhealth Uhealth 2020 Jan 30;8(1):e12884 [FREE Full text] [doi: 10.2196/12884] [Medline: 32003750]

76. Rohde A, Duensing A, Dawczynski C, Godemann J, Lorkowski S, Brombach C. An App to Improve Eating Habits of Adolescents and Young Adults (Challenge to Go): Systematic Development of a Theory-Based and Target Group-Adapted Mobile App Intervention. JMIR Mhealth Uhealth 2019 Aug 12;7(8):e11575 [FREE Full text] [doi: 10.2196/11575] [Medline: 30903746]

77. Zhao J, Freeman B, Li M. Can Mobile Phone Apps Influence People's Health Behavior Change? An Evidence Review. J Med Internet Res 2016 Oct 31;18(11):e287 [FREE Full text] [doi: 10.2196/jmir.5692] [Medline: 27806926]

78. Hankins M, Fraser A, Hodson A, Hooley C, Smith H. Measuring patient satisfaction for the Quality and Outcomes Framework. Br J Gen Pract 2007 Sep;57(542):737-740 [FREE Full text] [Medline: 17761061]

79. Graham B. Defining and Measuring Patient Satisfaction. J Hand Surg Am 2016 Sep;41(9):929-931. [doi: 10.1016/j.jhsa.2016.07.109] [Medline: 27570227]

80. Batbaatar E, Dorjdagva J, Luvsannyam A, Amenta P. Conceptualisation of patient satisfaction: a systematic narrative literature review. Perspect Public Health 2015 Sep;135(5):243-250. [doi: 10.1177/1757913915594196] [Medline: 26187638]

81. Staniszewska S, Brett J, Mockford C, Barber R. The GRIPP checklist: strengthening the quality of patient and public involvement reporting in research. Int J Technol Assess Health Care 2011 Oct;27(4):391-399. [doi: 10.1017/S0266462311000481] [Medline: 22004782]

82. Domecq JP, Prutsky G, Elraiyah T, Wang Z, Nabhan M, Shippee N, et al. Patient engagement in research: a systematic review. BMC Health Serv Res 2014 Feb 26;14:89 [FREE Full text] [doi: 10.1186/1472-6963-14-89] [Medline: 24568690]

83. Fergusson D, Monfaredi Z, Pussegoda K, Garritty C, Lyddiatt A, Shea B, et al. The prevalence of patient engagement in published trials: a systematic review. Res Involv Engagem 2018;4:17 [FREE Full text] [doi: 10.1186/s40900-018-0099-x] [Medline: 29796308]

84. Lee DJ, Avulova S, Conwill R, Barocas DA. Patient engagement in the design and execution of urologic oncology research. Urol Oncol 2017 Sep;35(9):552-558. [doi: 10.1016/j.urolonc.2017.07.002] [Medline: 28755961]

85. Sheridan S, Schrandt S, Forsythe L, Hilliard TS, Paez KA, Advisory Panel on Patient Engagement (2013 inaugural panel). The PCORI Engagement Rubric: Promising Practices for Partnering in Research. Ann Fam Med 2017 Mar;15(2):165-170 [FREE Full text] [doi: 10.1370/afm.2042] [Medline: 28289118]

86. Forsythe LP, Carman KL, Szydlowski V, Fayish L, Davidson L, Hickam DH, et al. Patient Engagement In Research: Early Findings From The Patient-Centered Outcomes Research Institute. Health Aff (Millwood) 2019 Mar;38(3):359-367. [doi: 10.1377/hlthaff.2018.05067] [Medline: 30830822]

87. Hemphill R, Forsythe LP, Heckert AL, Amolegbe A, Maurer M, Carman KL, et al. What motivates patients and caregivers to engage in health research and how engagement affects their lives: Qualitative survey findings. Health Expect 2020 Apr;23(2):328-336 [FREE Full text] [doi: 10.1111/hex.12979] [Medline: 31800154]

88. Batalden M, Batalden P, Margolis P, Seid M, Armstrong G, Opipari-Arrigan L, et al. Coproduction of healthcare service. BMJ Qual Saf 2016 Jul 16;25(7):509-517 [FREE Full text] [doi: 10.1136/bmjqs-2015-004315] [Medline: 26376674] 
89. Radl-Karimi C, Nicolaisen A, Sodemann M, Batalden P, von Plessen C. Coproduction of healthcare service with immigrant patients: protocol of a scoping review. BMJ Open 2018 Feb 03;8(2):e019519 [FREE Full text] [doi:

10.1136/bmjopen-2017-019519] [Medline: 29431137]

90. Policy for device software functions and mobile medical applications. US Food and Drug Administration. 2019 Sep 26.

URL: http://www.fda.gov/regulatory-information/search-fda-guidance-documents/

policy-device-software-functions-and-mobile-medical-applications [accessed 2020-11-03]

91. Public COTGPOMH. Shaping Europe's digital future - Policy- mHealth. European Commission. 2017 May 09. URL: https://ec.europa.eu/digital-single-market/en/mhealth [accessed 2020-11-03]

92. Developing an approach for using health technology assessments in reimbursement systems for medical products. World Health Organization. 2015 Oct. URL: http://www.who.int/medicines/areas/access/WHO_EMP_PAU_2015_5/en/ [accessed 2020-11-03]

93. Shaping Europe's digital future: Call for Expression of Interesttablishing a working group on mHealth assessment guidelines. European Commission. 2015 Oct 30. URL: https:/ec.europa.eu/digital-single-market/en/news/ call-expression-interest-establishing-working-group-mhealth-assessment-guidelines [accessed 2020-11-03]

94. International Patient Decision Aids Standards (IPDAS) Collaboration. URL: http://ipdas.ohri.ca/ [accessed 2020-11-03]

95. Ghafur S, Schneider EC. Engaging Patients Using Digital Technology - Learning From Other Industries. NEJM Catalyst. 2019 Jun 05. URL: https://catalyst.nejm.org/patients-digital-consumer-focused-industries/ [accessed 2020-11-03]

\title{
Abbreviations \\ DBCI: digital behavior change intervention \\ IOM: Institute of Medicine \\ IPDAS: International Patient Decision Aids \\ mHealth: mobile health
}

\author{
Edited by G Eysenbach, L Buis; submitted 20.12.19; peer-reviewed by R Buie, V Yim; comments to author 23.03.20; revised version \\ received 11.04.20; accepted 23.10.20; published 11.11.20 \\ Please cite as: \\ Bruce C, Harrison P, Giammattei C, Desai SN, Sol JR, Jones S, Schwartz R \\ Evaluating Patient-Centered Mobile Health Technologies: Definitions, Methodologies, and Outcomes \\ JMIR Mhealth Uhealth 2020;8(11):e17577 \\ URL: http://mhealth.jmir.org/2020/11/e17577/ \\ doi: $10.2196 / 17577$ \\ PMID: $\underline{3174846}$
}

(C) Courtenay Bruce, Patricia Harrison, Charlie Giammattei, Shetal-Nicholas Desai, Joshua R Sol, Stephen Jones, Roberta Schwartz. Originally published in JMIR mHealth and uHealth (http://mhealth.jmir.org), 11.11.2020. This is an open-access article distributed under the terms of the Creative Commons Attribution License (https://creativecommons.org/licenses/by/4.0/), which permits unrestricted use, distribution, and reproduction in any medium, provided the original work, first published in JMIR mHealth and uHealth, is properly cited. The complete bibliographic information, a link to the original publication on http://mhealth.jmir.org/, as well as this copyright and license information must be included. 